\title{
Enhancing Life Cycle Management Through the Symbiotic Use of Data Envelopment Analysis: Novel Advances in LCA + DEA
}

\author{
Cristina Álvarez-Rodríguez, Mario Martín-Gamboa, and Diego Iribarren
}

\begin{abstract}
The combined use of Life Cycle Assessment and Data Envelopment Analysis (LCA + DEA) arises as a growing field of research when evaluating multiple similar entities under the umbrella of eco-efficiency and sustainability. This chapter revisits a set of four recent LCA + DEA articles within the tertiary sector to explore the novel advances offered regarding the application of the well-established five-step LCA + DEA method for enhanced sustainability benchmarking. These advances - which relate to the DEA stage of the framework - include the calculation of gradual benchmarks for continuous improvement, the period-oriented benchmarking of unidivisional or multidivisional entities, and the implementation of decision-makers' preferences in the assessment. Overall, these advances further stress the suitability of using DEA to enhance the capabilities of LCA for the sustainability-oriented management of multiple similar entities.
\end{abstract}

\section{Introduction}

It is generally acknowledged that life cycle approaches could benefit from the combined use of other non-life cycle approaches in order to enrich decision-making processes [1]. In particular, a growing interest is found in scientific literature regarding the synergetic application of Life Cycle Assessment (LCA) and Data Envelopment Analysis (DEA) when evaluating multiple similar entities (usually

\footnotetext{
C. Álvarez-Rodríguez

Rey Juan Carlos University, Chemical and Environmental Engineering Group,

Móstoles, Spain

M. Martín-Gamboa

Department of Environment and Planning, University of Aveiro, Centre for Environmental and Marine Studies (CESAM), Aveiro, Portugal

D. Iribarren $(\triangle)$

IMDEA Energy, Systems Analysis Unit, Móstoles, Spain

e-mail: diego.iribarren@imdea.org
} 
called decision-making units, DMUs). In this regard, the symbiotic use of DEA - a linear programming methodology to calculate the relative efficiency of multiple resembling entities [2] - leads to enhance multi-criteria decision analysis by strengthening the capabilities of LCA for the eco-efficiency and sustainability management of entities.

The available reviews in the field of LCA + DEA show an increasing global interest in this area, with a growing number of case studies mainly in the primary [3] and energy [4] sectors. On the other hand, a lack of LCA + DEA studies within the tertiary sector was identified as a knowledge gap, but recently filled by a set of works addressing the sustainability-oriented management and benchmarking of retail stores as single or network (supply chain) structures [5-8]. The goal of this chapter is to explore the novel advances linked to the DEA stage of the LCA + DEA framework for enhanced sustainability benchmarking of entities by revisiting this recent set of case studies within the tertiary sector.

\section{Methodology}

This chapter focuses on the potentials behind the implementation - in references [5-8] - of specific DEA models that had never been used before within the wellestablished five-step LCA + DEA framework. As shown in Fig. 1, this LCA + DEA

Fig. 1 Five-step LCA + DEA methodological framework and novel advancements at the DEA stage

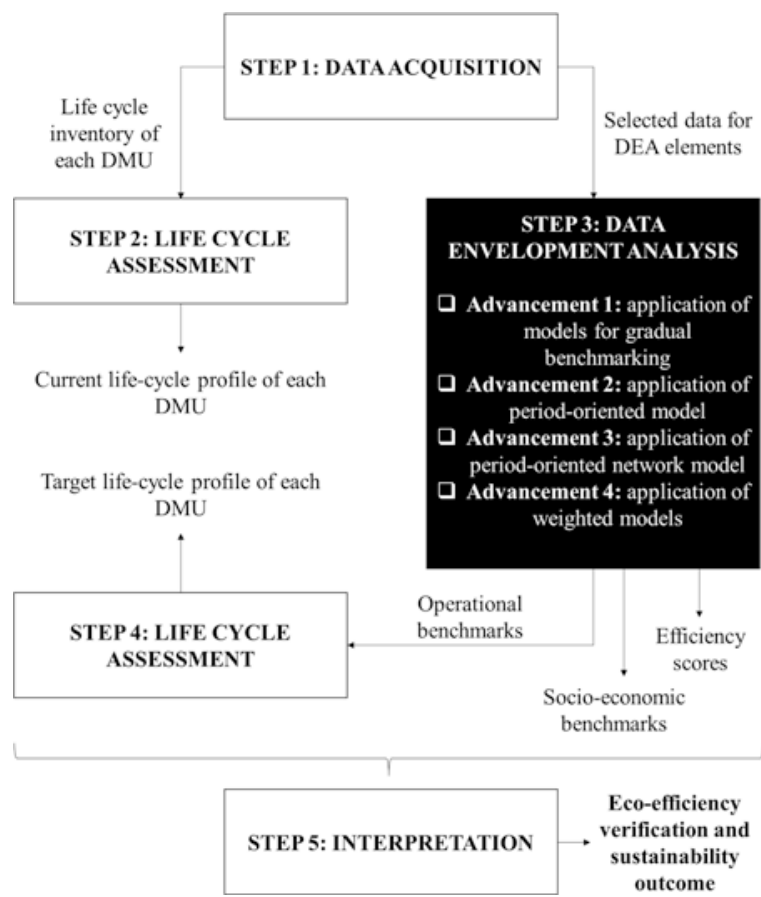


framework involves five common stages [9]: (i) data collection for each entity under assessment (i.e., DMU) to build life cycle inventories and DEA matrices; (ii) life cycle assessment of each of the DMUs to evaluate their current life cycle profile; (iii) data envelopment analysis to compute relative efficiency scores $\phi-$ allowing the discrimination between efficient $(\phi=1)$ and inefficient $(\phi<1)$ DMUs - and operational and socioeconomic benchmarks (i.e., target values that would turn inefficient DMUs into efficient); (iv) life cycle assessment using life cycle inventories modified according to the operational benchmarks from the previous step, thus resulting in target life cycle profiles (or environmental benchmarks); and (v) interpretation under the umbrella of eco-efficiency and sustainability.

As mentioned above, and also highlighted in Fig. 1, the advancements reviewed in this chapter refer mainly to the DEA stage. In other words, each advancement is primarily associated with the use of specific DEA models in each original study: (i) use of DEA models for gradual benchmarking in [5], (ii) use of a period-oriented model in [6], (iii) use of a period-oriented network model in [7], and (iv) use of weighted models in [8].

Given the specific relevance of the DEA stage of the original studies, Fig. 2 shows the commonalities and singularities of these studies at this stage. Key commonalities include the inclusion of at least the store operation division for at least one annual term (year 2017) and with a common set of DEA elements. Moreover,

Fig. 2 Commonalities and singularities at the DEA stage of the revisited studies

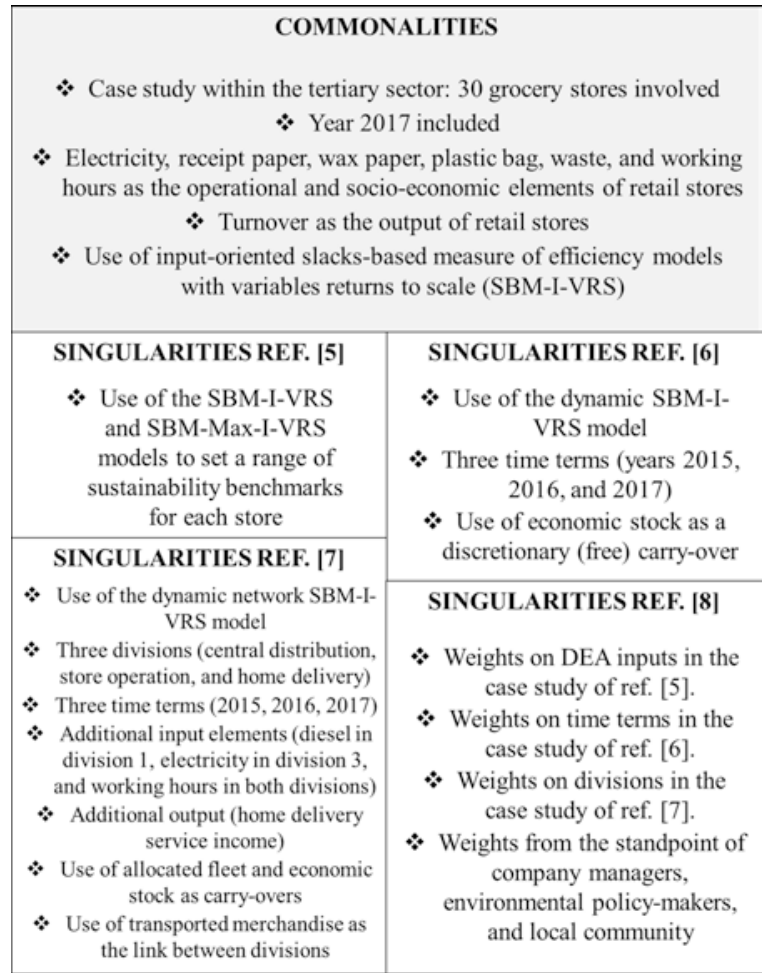


all these studies use input-oriented slacks-based measure of efficiency models with variables returns to scale (SBM-I-VRS), pursuing a reduction in the DEA inputs' levels while at least maintaining the same desirable output level. However, each study uses a specific SBM-I-VRS variant [10-13], which arises as a key singularity of each study: (i) use of both the conventional static SBM-I-VRS model and the alternative static SBM-Max-I-VRS model in [5] for the computation of gradual operational and socioeconomic benchmarks of retail stores, (ii) use of the dynamic SBM-I-VRS model in [6] for period-oriented sustainability benchmarking of retail stores, (iii) use of the dynamic network SBM-I-VRS model in [7] for period-oriented sustainability benchmarking of retail supply chains, and (iv) use of weighted SBMI-VRS models/matrices to implement weights on DEA elements, time terms, or divisions according to decision-makers' preferences from the standpoint of company managers, environmental policy-makers, or local community.

It should be noted that, even though the focus is placed on the DEA stage of the five-step LCA + DEA framework, the different operational benchmarks from the DEA step directly affect the calculation of the environmental benchmarks in the fourth step and therefore the sustainability outcome of each study. Further details on the novel potentials behind each study are provided in Sect. 3 .

\section{Results and Discussion}

Table 1 summarizes the main potentials associated with each of the studies reviewed. As a key potential linked to the use of both the conventional SBM-I-VRS model [10] and the alternative SBM-Max-I-VRS model [11], gradual sustainability benchmarking refers to the calculation - at the DEA stage - of a range of operational and socioeconomic target values (i.e., benchmarks) for each inefficient DMU. Furthermore, these gradual operational benchmarks are subsequently translated into environmental benchmarks through LCA (fourth step of the methodological framework). The computation of gradual sustainability benchmarks avoids pursuing too ambitious target values from the beginning, rationing the pursuit of efficiency and thereby promoting continuous improvement practices.

As another key potential - in this case linked to the use of the dynamic SBM-IVRS model [12] - period-oriented sustainability benchmarking means the

Table 1 Main potentials of the novel advancements identified in LCA + DEA

\begin{tabular}{l|l}
\hline Source & Novel LCA + DEA potential \\
\hline$[5]$ & $\begin{array}{l}\text { Gradual sustainability benchmarking for continuous } \\
\text { improvement }\end{array}$ \\
\hline$[6]$ & Period-oriented sustainability benchmarking \\
\hline$[7]$ & $\begin{array}{l}\text { Network sustainability benchmarking for complex } \\
\text { structures such as supply chains }\end{array}$ \\
\hline$[8]$ & $\begin{array}{l}\text { Effective implementation of decision-makers' preferences } \\
\text { (weights) }\end{array}$ \\
\hline
\end{tabular}


calculation, for each inefficient DMU, of operational, socioeconomic, and environmental benchmarks not only for a time term but to a number of time terms with a continuity condition between consecutive terms [14]. This allows taking into account efficiency changes over time, adapting sustainability management accordingly. Furthermore, when the DMUs are multidivisional (e.g., retail supply chains) and therefore a (dynamic) network model is used [13], this is specifically called (period-oriented) network sustainability benchmarking, as a distinction from the (period-oriented) sustainability benchmarking of unidivisional DMUs such as retail stores. The consideration of a network structure allows analysts to address the management of potentially complex entities involving interconnected processes, herein understood as divisions.

The last potential addressed in this chapter refers to the feasibility (and advisability) of implementing decision-makers' preferences (i.e., weights) in LCA + DEA studies. In this sense, the direct involvement of decision-makers such as company managers and policy-makers in an LCA + DEA study arises as a valuable asset. In fact, when decision-makers are effectively involved in the analysis, the use of weighting approaches - in addition to the default approach of equal weights - is highly recommended [8].

Finally, Table 2 summarizes the main conclusions and/or recommendations drawn from the novel LCA + DEA studies revisited in this chapter. Overall, the state of the art in LCA + DEA offers a wide range of opportunities for the sustainabilityoriented management and benchmarking of multiple similar entities, fully aligning this symbiotic methodological framework with the most relevant international initiatives such as the United Nations' Sustainable Development Goals (e.g., SDG 12 on sustainable consumption and production patterns) [15] and the European Green Deal (e.g., reducing the risk of greenwashing) [16]. Moreover, further room for new potentials is still expected, which is closely linked to the wide range of life cycle approaches and DEA models available now and in the future [1].

Table 2 Main conclusions and recommendations from novel LCA + DEA studies

\begin{tabular}{l|l}
\hline Source & Main conclusions/recommendations \\
\hline$[5]$ & $\begin{array}{l}\text { High applicability of the LCA + DEA methodology to the service sector } \\
\text { Feasibility of using the SBM-Max model within the LCA + DEA framework as a useful } \\
\text { tool for gradual multidimensional benchmarking of resembling entities for continuous } \\
\text { improvement }\end{array}$ \\
\hline$[6]$ & $\begin{array}{l}\text { Suitability of the LCA + DEA methodology for period-oriented sustainability } \\
\text { management and benchmarking of similar entities }\end{array}$ \\
\hline$[7]$ & $\begin{array}{l}\text { General recommendation of enriching LCA + DEA studies by moving from } \\
\text { unidivisional DMUs to multidivisional ones }\end{array}$ \\
\hline$[8]$ & $\begin{array}{l}\text { General recommendation of enriching conventional LCA + DEA studies (which use } \\
\text { equal weights by default) by implementing preferences from the decision-makers } \\
\text { involved in the analysis }\end{array}$ \\
\hline
\end{tabular}




\section{Conclusions}

The novel advances explored in this chapter contribute to further strengthening the symbiosis between LCA and DEA, providing valuable general recommendations in this growing field of research. Hence, these advances are expected to boost the applicability of LCA + DEA for enhanced life cycle management, e.g., at the company level. Finally, although these advances lead to increase the interest in LCA + DEA, a high number of potentials - at the level of both methodological choices and case studies addressing new DMU categories - still remain to be unveiled.

Acknowledgments This research has been partly supported by the Spanish Ministry of Economy, Industry and Competitiveness (ENE2015-74607-JIN AEI/FEDER/UE). Dr. Martín Gamboa states that thanks are due to FCT/MCTES for the financial support to CESAM (UID/AMB/50017/2019) through national funds.

\section{References}

1. Berlin, J., \& Iribarren, D. (2018). Potentials and limitations of combined life cycle approaches and multi-dimensional assessment. In Designing sustainable technologies, products and policies (pp. 313-316).

2. Cooper, W. W., Seiford, L. M., \& Tone, K. (2007). Data envelopment analysis: A comprehensive text with models, applications, references and DEA-solver software. Springer.

3. Vázquez-Rowe, I., \& Iribarren, D. (2015). Review of life-cycle approaches coupled with data envelopment analysis: launching the CFP + DEA method for energy policy making. Scientific World Journal, 813921.

4. Martín-Gamboa, M., Iribarren, D., García-Gusano, D., \& Dufour, J. (2017). A review of life-cycle approaches coupled with data envelopment analysis within multi-criteria decision analysis for sustainability assessment of energy systems. Journal of Cleaner Production, 150, 164-174.

5. Álvarez-Rodríguez, C., Martín-Gamboa, M., \& Iribarren, D. (2019). Combined use of data envelopment analysis and life cycle assessment for operational and environmental benchmarking in the service sector: A case study of grocery stores. Science of the Total Environment, 667, 799-808.

6. Álvarez-Rodríguez, C., Martín-Gamboa, M., \& Iribarren, D. (2019). Sustainability-oriented management of retail stores through the combination of life cycle assessment and dynamic data envelopment analysis. Science of the Total Environment, 683, 49-60.

7. Álvarez-Rodríguez, C., Martín-Gamboa, M., \& Iribarren, D. (2020). Sustainability-oriented efficiency of retail supply chains: A combination of life cycle assessment and dynamic network data envelopment analysis. Science of the Total Environment, 705, 135977.

8. Álvarez-Rodríguez, C., Martín-Gamboa, M., \& Iribarren, D. (2020). Sensitivity of operational and environmental benchmarks of retail stores to decision-makers' preferences through data envelopment analysis. Science of the Total Environment, 718, 137330.

9. Vázquez-Rowe, I., Iribarren, D., Moreira, M. T., \& Feijoo, G. (2010). Combined application of life cycle assessment and data envelopment analysis as a methodological approach for the assessment of fisheries. International Journal of Life Cycle Assessment, 15, 272-283.

10. Tone, K. (2001). A slacks-based measure of efficiency in data envelopment analysis. European Journal of Operational Research, 130, 498-509. 
11. Tone, K. (2016). Data envelopment analysis as a Kaizen tool: SBM variations revisited. Bulletin of Mathematical Sciences and Applications, 16, 49-61.

12. Tone, K., \& Tsutsui, M. (2010). Dynamic DEA: A slacks-based measure approach. Omega, 38, $145-156$.

13. Tone, K., \& Tsutsui, M. (2014). Dynamic DEA with network structure: A slacks-based measure approach. Omega, 42, 124-131.

14. Martín-Gamboa, M., \& Iribarren, D. (2016). Dynamic ecocentric assessment combining emergy and data envelopment analysis: Application to wind farms. Resources, 5, 8.

15. https://sustainabledevelopment.un.org/sdgs. Accessed 20.02.2020.

16. https://ec.europa.eu/info/sites/info/files/european-green-deal-communication_en.pdf. Accessed 20.02.2020.

Open Access This chapter is licensed under the terms of the Creative Commons Attribution 4.0 International License (http://creativecommons.org/licenses/by/4.0/), which permits use, sharing, adaptation, distribution and reproduction in any medium or format, as long as you give appropriate credit to the original author(s) and the source, provide a link to the Creative Commons license and indicate if changes were made.

The images or other third party material in this chapter are included in the chapter's Creative Commons license, unless indicated otherwise in a credit line to the material. If material is not included in the chapter's Creative Commons license and your intended use is not permitted by statutory regulation or exceeds the permitted use, you will need to obtain permission directly from the copyright holder. 